Published in final edited form as:

Qual Life Res. 2013 August ; 22(6): 1307-1312. doi:10.1007/s11136-012-0258-8.

\title{
Interpersonal discrimination and health-related quality of life among black and white men and women in the United States
}

\author{
Sherrill L. Sellers, \\ Miami University-Ohio, Oxford, OH 45056, USA \\ Dasha Cherepanov, \\ Partnership for Health Analytic Research, LLC, Beverly Hills CA, USA \\ Janel Hanmer, \\ Department of Internal Medicine, University of lowa Hospitals and Clinics, lowa City, IA 52242 , \\ USA \\ Dennis G. Fryback, and \\ University of Wisconsin-Madison, Madison, WI 53724, USA \\ Mari Palta \\ University of Wisconsin-Madison, Madison, WI 53724, USA \\ Sherrill L. Sellers: slsellers@muohio.edu; Dasha Cherepanov: dgcherepanov@gmail.com; Janel Hanmer: janel- \\ hanmer@uiowa.edu; Dennis G. Fryback: dfryback@wisc.edu; Mari Palta:mpalta@facstaff.wisc.edu
}

\section{Abstract}

Objective-We assessed associations between discrimination and health-related quality of life among black and white men and women in the United States.

Methods-We examined data from the National Health Measurement Study, a nationally representative sample of 3,648 adults aged 35-89 in the non-institutionalized US population. These data include self-reported lifetime and everyday discrimination as well as several health utility indexes (EQ-5D, HUI3, and SF-6D). Multiple regression was used to compute mean health utility scores adjusted for age, income, education, and chronic diseases for each race-by-gender subgroup.

Results-Black men and women reported more discrimination than white men and women. Health utility tended to be worse as reported discrimination increased. With a few exceptions, differences between mean health utility scores in the lowest and highest discrimination groups exceeded the 0.03 difference generally considered to be a clinically significant difference.

Conclusions-Persons who experienced discrimination tended to score lower on health utility measures. The study also revealed a complex relationship between experiences of discrimination and race and gender. Because of these differential social and demographic relationships caution is urged when interpreting self-rated health measures in research, clinical, and policy settings.

\section{Keywords}

Health-related quality of life; Interpersonal; discrimination; Race and gender differences

\section{INTRODUCTION}

Health related quality of life (HRQL) measures, which include disease specific measures, generic health status measures (e.g., SF-36), and preference-based utility measures (e.g., EQ-5D), are used to evaluate clinical outcomes, determine the burden of disease in a population, and quantify health for economic analysis. ${ }^{1}$ Studies suggest disparities in HRQL 
with low scores for those of lower income and education compared to those of higher socioeconomic status, for blacks compared to whites, and for women compared to men. ${ }^{2-5}$

Little is known about the mechanisms that underlie these race and gender differences. 6,7 One factor found to be associated with disparities in health is experience of discrimination. Conceptualized as a social stress, discrimination has been associated with poorer physical and mental health. ${ }^{8,9}$ Yet the prevalence of discrimination across demographic characteristics in the United States (U.S.) is poorly described. ${ }^{10}$ In studies using the everyday and lifetime discrimination scales, the most consistent finding is that whites report experiencing less discrimination than non-whites. ${ }^{9,10}$ Although less consistently found, it appears that prevalence of discrimination may vary by gender. ${ }^{11,12,13}$ Although black men and women were equally likely to perceive general workplace discrimination or mistreatment when shopping in public, ${ }^{14}$ black men appear more likely to perceive themselves to face racial discrimination in hiring and in encounters with the police. ${ }^{15}$

Few discrimination studies have sufficient sample sizes to simultaneously consider subgroups by race and gender and none have evaluated HRQL. Race and gender are both associated with a range of constrained opportunities and resources, such as differential social capital and exposure to social risks such as discrimination that influence daily life, perceptions, attitudes, health, and well being. ${ }^{16,17,18} \mathrm{~A}$ more complete understanding of disparities in HRQL requires attention to the intersection of race and gender and experiences of discrimination. We examine our hypothesis that perceived discrimination is associated with lower HRQL scores among black and white men and women from a US sample of adults.

\section{METHODS}

\section{Data}

We used cross-sectional data from the U.S. National Health Measurement Study (NHMS) ${ }^{19}$ on respondents self-identifying as either African American/black or white. The NHMS was a random-digit dialed telephone survey, conducted in 2005-2006, of 3844 community-living US adults aged 35-89 years. The NHMS collected self-reported data on interpersonal discrimination, socioeconomic status, presence of health conditions, and several widely-used generic HRQL instruments. NHMS data are publicly available (http://www.icpsr.umich.edu/ cocoon/NACDA/STUDY/23263.xml).

\section{Health Utility Measures}

This study examined three commonly used utility measures of HRQL: the EuroQol EQ-5D (EQ-5D) $^{20,21}$, the Health Utilities Index Mark 3 (HUI3) ${ }^{22}$, and the SF-6D, computed from the SF-36v2 ${ }^{\mathrm{TM}} 23,24$. The EQ-5D, HUI3, and SF-6D are all generic measures, i.e., not specific to any one organ system or disease, and preference-based, i.e., their scoring is based on systematically elicited utility evaluations by people sampled from a community or the general population. All three produce summary utility scores anchoring "dead" at 0 and "full health" at 1.0.

The EQ-5D (http://www.euroqol.org) has 5 questions, each with 3 response categories: no problem, some problem, or severe problem. The questions refer to "your health today" and ask about mobility, self-care, usual activities, pain/discomfort, and anxiety/depression. We use the scoring algorithm that was derived in a population sample of 4000 US adults. ${ }^{21}$

The HUI3 (http://www.healthutilities.com/) questions refer to "your level of ability or disability during the past week" and access health status on eight attributes: vision, hearing, speech, ambulation, dexterity, emotion, cognition, and pain with 5 or 6 levels per attribute, 
varying from highly impaired to normal. ${ }^{22}$ The scoring algorithm for the HUI3 was derived in a community sample from Hamilton, Ontario, Canada.

The SF-36v2 $2^{\mathrm{TM}}$ health status questionnaire (http://www.sf-36.org/), consisting of 36 questions generally referring to health in the past 4 weeks, is usually scored as either 8 individual scales or 2 summary scores. Brazier et al. developed the SF-6D, a preferencebased scoring algorithm that yields a single summary score using 11 of the items from the SF-36 that define health status on 6 attributes: physical function, role limitation, social function, pain, mental health, and vitality. ${ }^{23,24}$ Scoring of the SF-6D is based on a population sample from the United Kingdom. ${ }^{23,24}$

\section{Discrimination Scales}

Two scales of interpersonal discrimination were administered to all respondents, the everyday discrimination scale and the lifetime discrimination scale (Table 1). ${ }^{25}$ Scores were computed by summing the numerical equivalents for the categorical responses; everyday discrimination scores range from 0 to 25 and lifetime discrimination scores range from 0 to 4 , with higher scores representing more discrimination.

\section{Covariates}

The NHMS also surveyed years of education ( $<12$ years, 12 years, $>12$ years), household income $(<25,000, \$ 25,000-\$ 50,000, \$ 50,000-\$ 75,000$, and $>\$ 75,000)$, and past diagnoses of health conditions. We included the 5 conditions with highest prevalence and impact on HRQL scores: coronary heart disease, arthritis, chronic respiratory disease (asthma, emphysema, and chronic bronchitis), diabetes, and stroke. ${ }^{26}$

\section{Analyses}

Means and percentages of discrimination and health utility scores were computed for four race and gender groups. Each race-by-gender group was further stratified by discrimination scores and mean health utility scores were estimated within each stratum using weighted least-squares multivariable regression to adjust for age, income, education, and conditions. All adjustment variables were centered to the NHMS weighted means for blacks and whites combined. All analyses were performed in SAS, incorporating survey weights to account for the NHMS sampling design (Copyright 2002-2003 SAS Institute Inc., Cary, NC, USA).

\section{RESULTS}

There were 3648 respondents: 2562 white and 1086 black (Table 2). The sample was predominantly women $(57.5 \%)$ with a mean age of 54.5 years. Black men reported the highest lifetime discrimination scores, followed by black women; white women tended to report the least lifetime discrimination. The distribution of everyday discrimination scores was very similar for black men and women and higher than whites' scores. Blacks also had lower income levels than whites. Black men and women reported significantly higher percentages of diabetes than their white counterparts. Black women reported significantly more chronic respiratory disease than other groups.

Health utility scores were worse at higher levels of everyday discrimination in all race-bygender strata for all HRQL measures except for EQ-5D among black men and white men (Table 3). For SF-6D and HUI3, differences between mean utilities in the lowest and highest discrimination groups exceeded 0.03 , a difference considered clinically significant 27,28

Higher lifetime discrimination scores were associated with worse health utility scores (Table 4). This difference reached statistical significance ( $\mathrm{p}<.05)$ for SF-6D and HUI3 in all groups, 
but not for EQ-5D in black men. All differences were deemed clinically significant, except for EQ-5D and SF-6D in white women.

\section{DISCUSSION}

We explored differences in HRQL by discrimination, within race and gender groups. We found higher discrimination was associated with lower health utility scores for blacks and whites, men and women. With a few exceptions, mean health utility score differences between lowest and highest everyday discrimination or lifetime discrimination levels in any race-gender strata exceeded 0.03 , a clinically significant difference for utility measures. This suggests that the stress of discrimination is pervasive by race and gender. ${ }^{29}$

Our study provides nationally-representative estimates of both everyday and lifetime discrimination for community-dwelling adults aged 35-89 years. Consistent with other studies, blacks report more discrimination than whites. ${ }^{10}$ Black men and women report similar levels of everyday discrimination, yet black men report more lifetime discrimination than black women. White women report the least lifetime discrimination. The high prevalence of discrimination among black men supports a recent theory on racial hierarchy which suggests that subordinate males are primary targets of discrimination and that discrimination is practiced to reduce competition for power. ${ }^{30}$

We were unable to assess causation. Poor health may heighten perceptions of unfair treatment, ${ }^{31}$ although evidence from longitudinal studies indicates that discrimination precedes poor health. ${ }^{32,33}$ Additionally, it is possible that the self-reported survey items in this study were perceived and used differently by race and gender. ${ }^{34,35,36}$ The small sample size for black men is another limitation. Longitudinal studies with diverse population groups are needed to assess causation and generalizability of the study findings.

Race and gender are important and intertwined social constructs that contribute to differences in health, possibly moderated by discrimination. ${ }^{37}$ Our study emphasizes the necessity for further studies and development of theory to explain the simultaneous impact of race, gender, and discrimination on health. We urge that extrapolation of health utility differences across these groups in research, clinical, and policy settings should be done with caution.

\section{References}

1. McDowell, I. Measuring Health: A guide to rating scales and questionnaires. New York: Oxford University Press; 2006.

2. Fu AZ, Kattan MW. Racial and ethnic differences in preference-based health status measure. Current Medical Research and Opinion. 2006; 22(12):2439-2448. [PubMed: 17257458]

3. Franks P, Gold MR, Fiscella K. Sociodemographics, Self-Rated Health, and Mortality in the U.S. Social Science and Medicine. 2003; 56(12):2505-14. [PubMed: 12742613]

4. Cherepanov D, Palta M, Fryback DG, Robert SA. Gender differences in health-related quality-oflife are partly explained by sociodemographic and socioeconomic variation between adult men and women in the US: evidence from four US nationally representative data sets. Quality of life research: an international journal of quality of life aspects of treatment, care and rehabilitation. 2010; 19(8):1115-24.

5. Robert SA, Cherepanov D, Palta M, Cross Dunham N, Feeny D, Fryback DG. Socioeconomic Status and Age Variations In Health-Related Quality Of Life: Results from The National Health Measurement Study. The Journals of Gerontology. Series B, Psychological Sciences and Social Science. 2009; 64(3):378-389.

6. Sellers, SL.; Newmann, JP. Role of material resources in race and gender differences in mental health. American Sociological Association; New York, New York: Aug. 2007 
7. Pereira CCA, Palta M, Mullahy J, Fryback DG. Race and preference-based health-related quality of life measures in the United States. Quality of Life Research. 2011; 20(6):969-78. [PubMed: 21181447]

8. Williams DR, Mohammed S. Discrimination and racial disparities in health: evidence and needed research. J Behavior Medicine. 2009; 32:20-47.

9. Sternthal MJ, Slopen N, Williams DR. Racial disparities in health: How much does stress really matter? Du Bois Review. 2011; 8(1):95-113.

10. Paradies Y. A systematic review of empirical research on self-reported racism and health. International J Epidemiology. 2006; 35:888-901.

11. Krieger N, Sidney S. Racial discrimination and blood pressure: the CARDIA Study of young black and white adults. Am J Public Health. 1996; 86:1370-78. [PubMed: 8876504]

12. Kessler RC, Mickelson KD, Williams DR. The prevalence, distribution, and mental health correlates of perceived discrimination in the United States. J Health Soc Behav. 1999; 40:208-30. [PubMed: 10513145]

13. Guyll M, Matthews KA, Bromberg JT. Discrimination and unfair treatment: relationship to cardiovascular reactivity among African American and European American woman. Health Psychology. 2001; 20:315-25. [PubMed: 11570645]

14. Carter RT. Racism and psychological and emotional injury: recognizing and assessing race-based traumatic stress. The Counseling Psychiatrist. 2007; 35(1):13-105.

15. Barnes LL, Mendes De Leon CF, Wilson RS, Bienias JL, Bennett DA, Evans DA. Racial differences in perceived discrimination in a community population of older blacks and whites. $\mathrm{J}$ Aging Health. 2004; 16:315-37. [PubMed: 15155065]

16. Williams DR, Mohammed J, Leavell J, Collins C. Race, socioeconomic status, and health: complexities, ongoing challenges, and research opportunities. Annals of the New York Academy of Sciences. 2010; 1186:69-101. [PubMed: 20201869]

17. Bird, DC.; Rieker, PP. Gender and health: The effects of constrained choices and social policies. New York: Cambridge University Press; 2008.

18. Barnes LL, Mendes de Leon CF, Lewis TT, et al. Perceived discrimination and mortality in a population-based study of older adults. Am J Public Health. 2008; 98:1241, 1247. [PubMed: 18511732]

19. Fryback DG, Dunham NC, Palta M, Hanmer J, Buechner J, Cherepanov D, Herrington SA, Hays RD, Kaplan RM, Ganiats TG, Feeny D, Kind P. US Norms for Six Generic Health-Related Quality-of-Life Indexes From the National Health Measurement Study. Medical Care. 2007; 45(12):1162-1170. [PubMed: 18007166]

20. Brooks, R.; Rabin, R.; de Charro, F. The Measurement and Valuation of Health Status Using EQ-5D: A European Perspective. Dordrecht. Netherlands: Kluwer Academics Publishers; 2003.

21. Shaw JW, Johnson JA, Coons SJ. US valuation of the EQ-5D health states: Development and testing of the D1 valuation model. Medical Care. 2005; 43(3):203-220. [PubMed: 15725977]

22. Feeny D, Furlong W, Torrance GW, Goldsmith CH, Zhu Z, DePauw S, Denton M, Boyle M. Multiattribute and single-attribute utility functions for the health utilities index mark 3 system. Medical Care. 2002; 40(2):113-28. [PubMed: 11802084]

23. Brazier J, Roberts J, Deverill M. The estimation of a preference-based measure of health from the SF-36. J Health Econ. 2002; 21(2):271-92. [PubMed: 11939242]

24. Brazier JE, Roberts J. The estimation of a preference-based measure of health from the SF-12. Medical Care. 2004; 42(9):851-9. [PubMed: 15319610]

25. Williams D, Yu Y, Jackson J, Anderson N. Racial differences in physical and mental health: Socioeconomic status, stress, and discrimination. J Health Psychology. 1997; 2(3):335-351.

26. Lubetkin EI, Jia H, Franks P, Gold MR. Relationship Among Sociodemographic Factors, Clinical Conditions, and Health-related Quality of Life: Examining the EQ-5D in the U.S. General Population. Quality of Life Research. 2005; 14(10):2187-2196. [PubMed: 16328899]

27. Walters S, Brazier J. Comparison of the minimally important difference for two health state utility measures: EQ-5D and SF-6D. Quality of Life Research. 2005; 14(6):1523-1532. [PubMed: 16110932] 
28. Guyatt GH, Walter S, Norman G. Measuring change over time: assessing the usefulness of evaluative instruments. J Chronic Disease. 1987; 40:171e8. [PubMed: 3818871]

29. De Vogli R, Ferrie JE, Chandola T, Kivimaki M, Marmot MG. Unfairness and health: Evidence from the Whitehall II Study. J Epidemiology and Community Health. 2007; 61:513-518.

30. Sidanius, J.; Veniegas, RC. Gender and Race Discrimination: The Interactive Nature of Disadvantage. In: Oskamp, S., editor. Reducing Prejudice and Discrimination: The Claremont Symposium on Applied Social Psychology. Mahwah, New Jersey: Lawrence Erlbaum Associates; 2000. p. 47-69.

31. Schulz A, Gravlee C, Williams D, Israel B, Mentz G, Rowe Z. Discrimination, symptoms of depression, and self-rated health among African America women in Detroit. Results from a longitudinal analysis. American J Public Health. 2006; 96(7):1265-1270.

32. Sechrist GB, Swim JK, Stangor C. When do the stigmatized make attributions to discrimination occurring to the self and others? The roles of self-presentation and need for control. J Personality and Social Psychology. 2004; 87:111-122.

33. Krieger N. Embodying inequality: A review of concepts, measures, and methods for studying health consequences of discrimination. International J Health Services. 1999; 29:295-352.

34. Fleishman J, Lawrence W. Demographic variation in SF-12 scores: True differences or differential item functioning? Medical Care. 2003; 41(7):75-86.

35. Fryback DG, Palta M, Cherepanov D, Bolt D, Kim J-S. Comparison of five health-related quality of life indexes using item response theory analysis. Medical Decision Making. 2010; 30(1):5-15. [PubMed: 19843961]

36. Lewis TT, Yang MF, Jacobs EA, Fittchett G. Racial/ethnic differences in responses to the everyday discrimination scale: A differential item functioning analysis. American Journal of Epidemiology. 2012; 175(5):391-401. [PubMed: 22306556]

37. Hankivsky O. Women's health, men's health, and gender and health: Implications of intersectionality. Social Science \& Medicine. 2012; (74):1712-1720. [PubMed: 22361090] 
Table 1

Everyday and Lifetime Discrimination Scales.

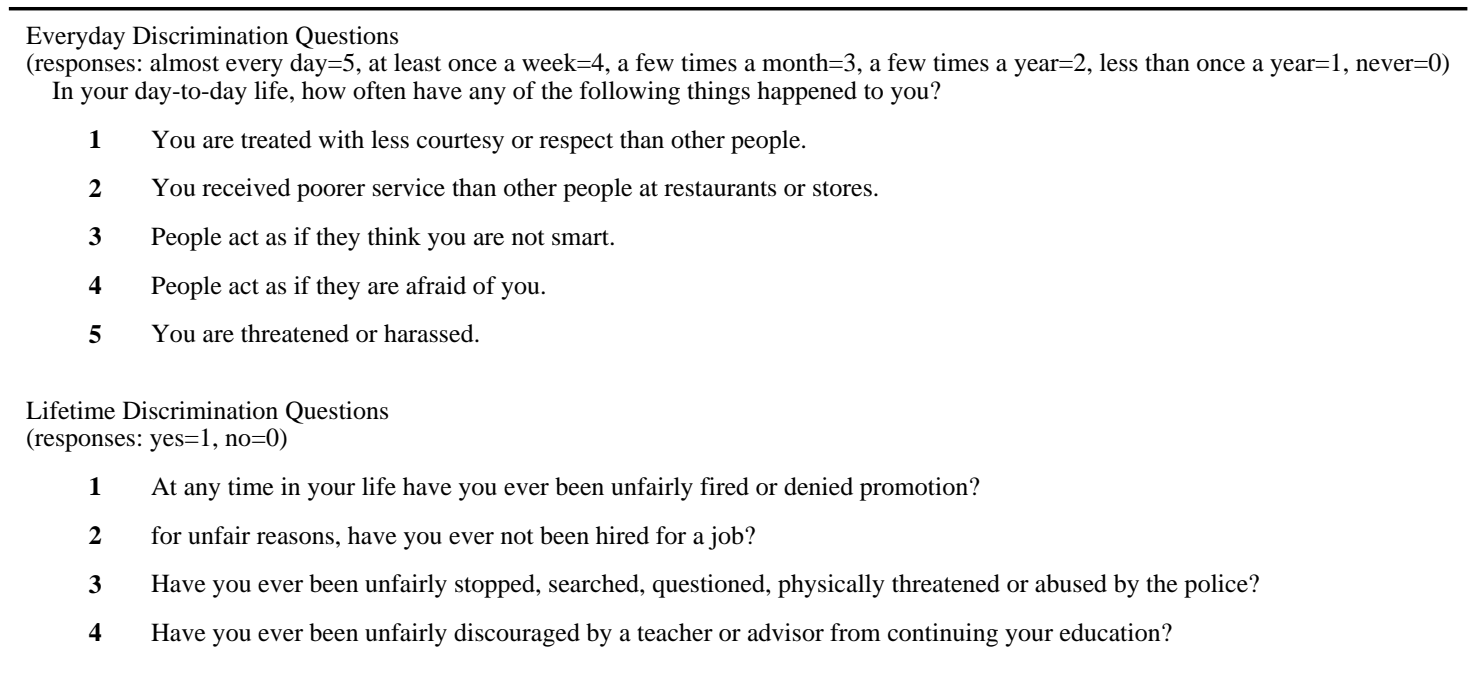




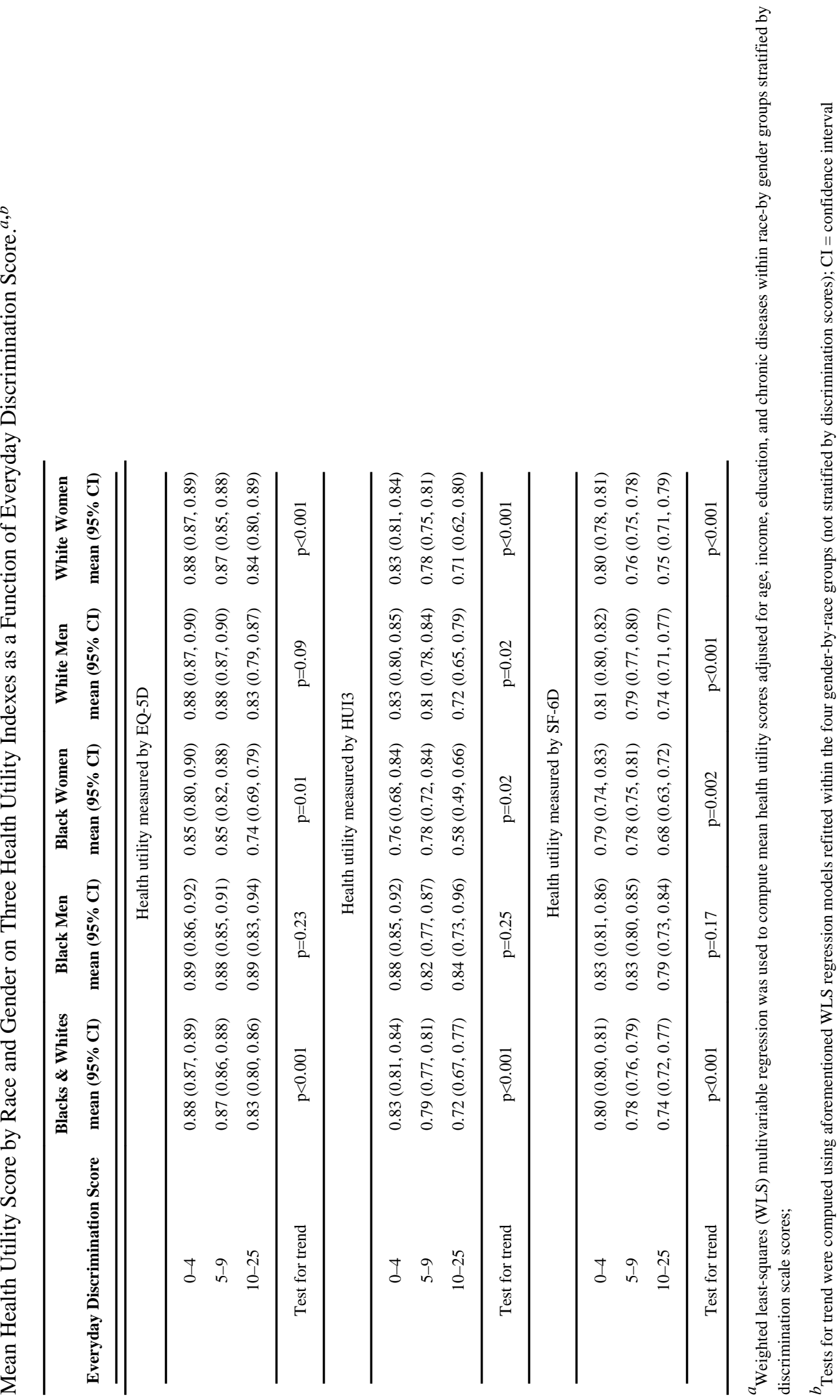




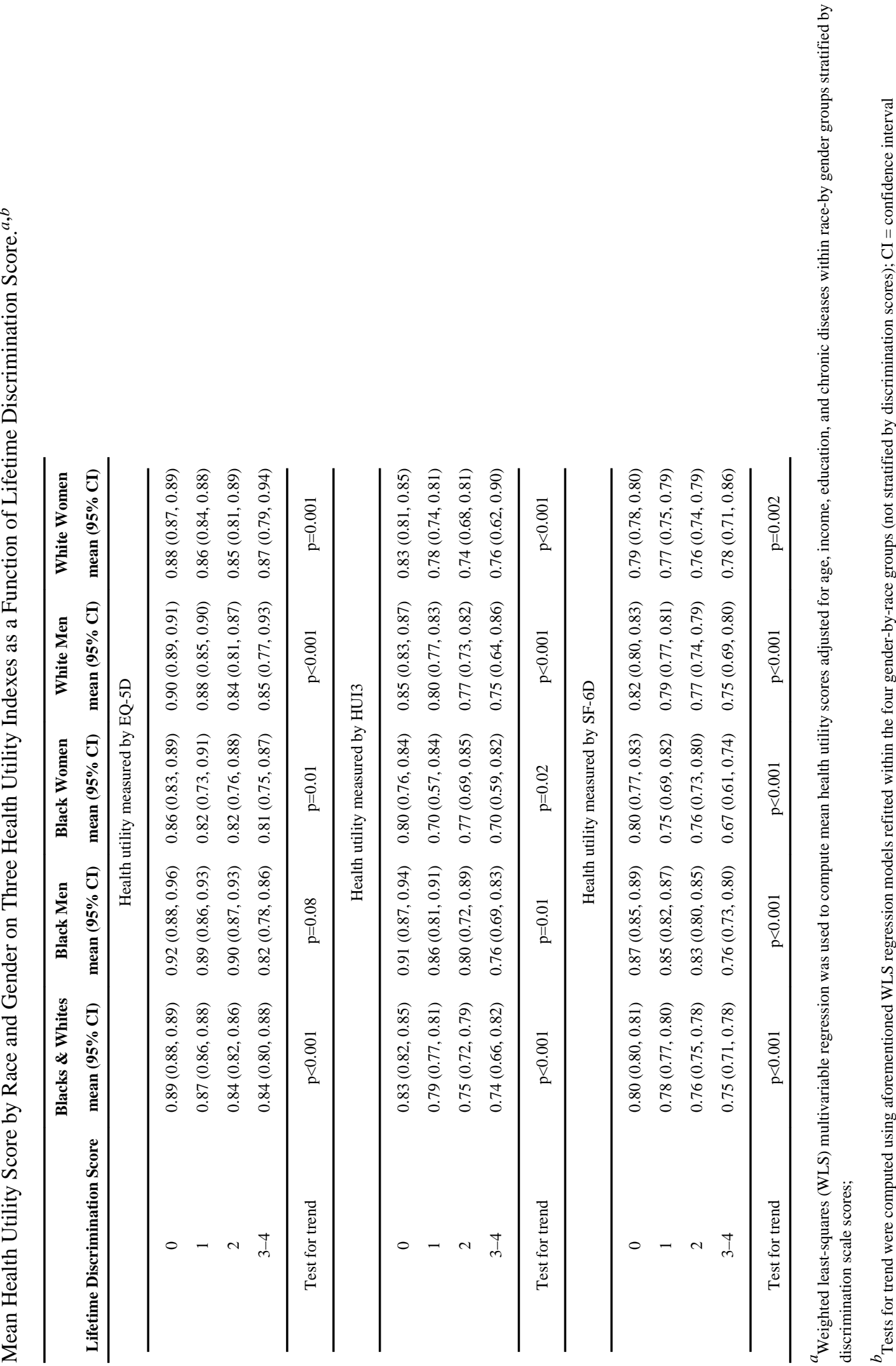

